\title{
DIFERENCIAS CULTURALES PARA INTERPRETAR \\ ALGUNOS FRACASOS DEL TRATAMIENTO DE LA TBC PULMONAR EN CHILE
}

\author{
Julio Munizaga
}

Durante 1972 en el Consultorio Quinta Bella, del Ministerio de Salud Pública, en Santiago, observé un problema que describo en este trabajo:

El personal del Consultorio, en su mayoría, estaba compuesto por profesionales jóvenes con pocos años de ejercicio y fuertemente motivados por avanzar interdisciplinariamente en las causas de alta incidencia de algunas enfermedades que, a juicio del equipo médico, persistían con tasas demasiado elevadas que no correspondían al nivel del tratamiento que la medicina científica prestaba.

Una de las mayores preocupaciones era el problema del abandono de los tratamientos por parte de los pacientes. Estos abandonos perjudicaban los avances logrados y producían ciclos de significativa desocupación y evidente "mal uso" de los stocks de medicina para los tratantes que figuraban como inscritos y desaparecían sin aviso. El abandono, además, implicaba prolongamiento innecesario $y$, muchas veces, retroceso en los niveles de avances logrados.

En especial la situación era más grave en el caso de los abandonos de tratamientos y la gran incidencia de la tuberculosis pulmonar. Se podría decir que existía un territorio inexplorado en el cual tanto el equipo de salud como el enfermo conocían, pero no se realizaban las acciones tendientes a clarificarlo. Este territorio, al cual hago referencia como problema central, estaba en el desconocimiento mutuo de los roles.

El equipo médico no tenía referencias claras sobre la conducta del rol del enfermo de tuberculosis pulmonar del conjunto de pacientes tratados. Por otra parte los enfermos desconocían con igual desacierto aspectos básicos del rol del equipo de salud. 
El desconocimiento mutuo señalado permitía una coexistencia disfuncional por cuanto ambos sistemas de roles atribuían a los otros expectativas de conductas esperadas que en realidad no tenían lugar. Este campo de conductas supuestas 0 ideales, lejos de clarificarse como antecedentes objetivos para el avance en la recuperación del enfermo, de la etiología de la alta incidencia y abandono, persistían creando así una especie de marco de trabajo, sin mayores preguntas ni respuestas sobre los problemas de tratamiento entre equipo médico y paciente y sin mayores peticiones de clarificaciones formales por parte del paciente, o del sistema de pacientes, porque se unían para planificar su rechazo al tratamiento, justificar el abandono del mismo, discutir manera de evadir los molestos resultados de la medicación y también intercambiar opiniones y experiencias sobre tratamientos no científicos.

En relación al problema del abandono del tratamiento por parte del enfermo tísico bronco pulmonar, el equipo médico no era indiferente e intentaban, mediante visitas practicadas por asistentes sociales, saber del paradero del reticente. Estas visitas no tenían el efecto esperado por cuanto, entre otras causas, los reticentes no les asignaban valor o el peso suficiente como para sentirse imperativamente compelidos a volver o tratarse.

El análisis aproximativo a esta situación en el Consultorio citado, si bien no permite una amplia generalización sobre el cómo evitar la situación descrita, al menos abrió algunas posibilidades que al explorarse permitirían, sin duda algunos cambios positivos en la relación médico-paciente y la salud y la cultura como problema de orden general.

\section{SALUD Y CULTURA}

Existe un consenso entre los estudiosos de la conducta humana de la fuerte acción modeladora que sobre ésta ejerce la cultura. Los salubristas públicos hoy hablan de la salud pública más bien como una ciencia social que una ciencia esencialmente biológica*.

Hoy en día el científico que actúa directamente en el campo de la salud humana ha debido dejar de considerar a los males orgánicos como problemas de naturaleza estrictamente biológica, sino que desde luego los enmarca en una dimensión más amplia multivarial en la cual los aspectos psicológicos sociales, medioambientales y sobre todo los aspectos sobre etiologías, tratamientos y concepciones populares de la enfermedad y su tratamiento y conductas consecuentes, son centrales.

En nuestra indagación sobre el problema de abandono de tratamiento y "recetas" populares estimamos oportuno comparar o contrastar el razonamiento cientí-

* Algunas Relaciones entre Medicina y Cultura Popular. Julio Munizaga B. En Revista Familia, Educación, Sociedad, editada por Centro Nacional de la Familia, 1974. 
fico, expresado en las acciones del equipo de salud, y el razonamiento popular expresado en conducta de asistencia y abandono y en las consecuentes bases no populares de formas y percepciones sobre el mal.

Podríamos decir que, en general, una característica del paciente o enfermo de sectores con educación básica o media incompleta en general es que tenderán como conducta típica a elaborar razones que vienen en definitiva a ser una especie de reflejo o contraparte de razonamiento científico. Esto en especial cuando las afecciones o males con una real o supuesta base orgánica escapan al control que sobre los mismos piensan o tienen realmente. De este contraste, favorecido por la actitud generalizada del científico en orden al mantener demasiados altos los muros intersubculturales, surge una especie de respuesta institucionalizada a nivel popular: abandono del tratamiento científico de la enfermedad, sobre todo si ésta es larga y por tanto de progreso lento.

Esta "atracción" o impulso por abandonar tratamientos científicos, por parte de la población se puede considerar una característica de la población nacional, proyectable a todos los estratos. Pero el abandono de esta modalidad de tratamiento está a su vez apoyado en una creencia diría muy generalizada, en nuestro medio, en relación a otras formas de "medicina" representadas por yerbateros, "médicos populares", adivinos, meicas, comadronas, etc., y el valor de la experiencia vivida por terceros ligados al enfermo. Terceros a los cuales este tiende a asignar credibilidad o veracidad: el compadre, los vecinos, los amigos fieles. Este que pudiera ser denominado sistema de credibilidad popular está fuertemente arraigado y puede, aparentemente, tener menor significación que la que se percibe en medio de un país que tiene institucionalizado por largos años un sistema de salud mixto con una alta cobertura de población.

Sumado a lo anterior deberíamos señalar que la actual actitud de medicina científica refuerza a las acciones populares de salud al facilitar la automedicación, que si bien es cierto conlleva peligros parece ser una vía más fácil y expedita que está al alcance de la mayoría de los enfermos reales o de los que creen estarlo.

Esta breve exposición la enmarcamos de preferencia en uno de los niveles en que Anderson y Seacat (1959) siguiendo a Sheps y Taylor (1954)* formulan la investigación en salud dividida en tres aspectos de igual importancia:

a) niveles de salud

b) valores, actitudes y prácticas en relación a la salud, y

c) personal, cuyas funciones son hacer algo por la salud, a través de algunos medios.

* En Salud y Conducta Humana. Steven Pulgar. Reproducido por la Cátedra de Administración de Salud Pública. Escuela de Salubridad. U. de Chile, 1966. Original inglés, 1962. 
Es decir, nos preocupamos en especial de indagar en el nivel de los valores, actitudes y prácticas en relación a la salud y el tratamiento de la TBC pulmonar en un Consultorio del Ministerio de Salud.

Científicos sociales de la salud en Chile como Solari y Marconi han formulado, muy precisamente, el marco cultural dentro del que puede explicarse en nuestro país, la dinámica, problemas, conflictos y desarrollo del área de salud. En efecto, en Chile había tres culturas: la indígena, la popular, y la de elite u oficial. A cada una corresponde un patrimonio de valores, creencias, conocimientos, concepciones etiológicas y terapéuticas de salud. Ahora bien, sucede que muchas veces, la cultura indígena de salud es presionada o esterilizada por la oficial. Lo mismo puede ocurrir a la popular (que sería la cultura de salud no indígena, pero no cientifica).

Sólo una concepción y articulación armónica de las tres culturas puede llevar a un adecuado desarrollo, prevención y terapia. Es seguro, como se advierte en estudios nacionales que la medicina (cultura) oficial de salud está incapacitada para abordar los problemas de los contingentes indigenas y también los de los contingentes populares. La "distancia" entre médicos y pueblo e indígenas es una distancia cultural.

\section{RAZONES DE ABANDONO DEL TRATAMIENTO}

En general las razones de abandono del tratamiento se enmarcan en un conjunto de causales cuya atingencia es relativa. Estas causales a su vez se usan como elementos justificatorios que tienden a modificarse según se trate del interlocutor al cual deben entregarlas. De todos modos prima una fuerte diferenciación entre las que señalan en sus domicilios y las que indica en el Consultorio.

Una de las causales más usadas es la del cambio de domicilio, que habría determinado según muchos de los abandonos la pérdida de acceso al Consultorio por cambiarse de jurisdicción.

Un segundo grupo de causas podriamos identificarla en el maltrato recibido en el Consultorio y en los problemas de contagio y de vergüenzas al ser expuestos en una sala común de espera con otros pacientes o visitas del Consultorio.

Un tercer grupo de causas está en el supuesto mal o daño que los medicamentos les causaban. Para algunos éstos eran tan fuertes que los declaraban insoportables. (Es efectivo que un tipo de estos medicamentos producía un cierto grado de malestar, pero no era insoportable como lo definían algunos enfermos).

Otro grupo de causas estaba en que la enfermedad permitía las largas licencias a través de la medicina preventiva y para algunos es más atractivo vivir en un marco de enfermedad semitratada y prolongar una situación que genera ingresos y no requiere de trabajo sistemático. 
Por último el grupo de causas de mayor incidencia y que de alguna u otra manera englobaba a las otras era determinada por el nivel de desconocimiento $e$ incomunicación existente en el box del médico entre éste y paciente y en el box del practicante y el enfermo. En ambos casos la situación presenciada podría sintetizarse de la siguiente manera: médico y paciente juntos en un box de reducido tamaño. Médico inspecciona una radiografía colgada ante un aparato para observarla. Paciente sentado mira la radiografía y, luego, alternadamente, el rostro del médico. Este fija su vista en la carpeta del paciente, mira radiografías anota, extiende receta y le pregunta al paciente cómo se ha sentido; luego le ordena Salga y vaya al practicante. Todo esto ha durado 10 a 12 minutos.

El paciente sale y hace cola ante la oficina del practicante. No sabe si avanzó o retrocedió en su enfermedad.

Lo que ha sucedido es que la cultura popular (del paciente) de tipo concreto, con concepciones fisiológicas, biológicas tradicionales no se ha articulado para nada con la cultura científica del médico. Aquí surge la necesidad de elementos intermediarios o "traductores" culturales (traducen la cultura abstracta y científica las recetas a términos concretos y populares). Estos elementos o bisagras culturales pueden ser las enfermeras o auxiliares.

\section{ALGUNOS CASOS DE ABANDONO}

Visitas a casos de abandono de tratamiento:

El lunes 18 de agosto.

\section{Señor F.D. (calle Recoleta)}

El Sr. Díaz fue encontrado en la dirección dada que corresponde a un plantel de Cadetes de la Asociación Central de Fútbol. Dentro se veía una cancha, pistas de carrera y algunos muchachos y muchachas con trajes de entrenamiento practicando ejercicios.

El Sr. D. al ser interrogado sobre su abandono de tratamiento expresó que no lo había abandonado que había creído que su tratamiento había finalizado al indicarle alguien en el consultorio que se preocupara por su libreta. Quedó de volver al día siguiente al Consultorio, pero por indicación mía lo haría el miércoles siguiente y así lo hizo.

Al Dr. Palaeneck le negó que me hubiera dicho que él creyó que su tratamiento había terminado. Y al practicante Sr. Rozas le dijo que la razón de su ausencia había sido el problema de la sequía en el norte, ya que tenía un terreno allá y el fenómeno lo había afectado mucho. Al médico le dijo que la razón de su ausencia obedecía a la tramitación de libreta. 
Se puede apreciar en el caso una situación de reconocimiento de la falta a tratamiento que trata de escudar dando múltiples justificaciones. Por otra parte según me dijo el Sr. Rozas este caso no está retirado y es actualmente funcionario de la Universidad de Chile.

Por otra parte se puede apreciar la peligrosidad potencial que encierra el hecho de que una persona con TBC se desenvuelva laboralmente con muchachos deportistas (jóvenes y sanos que buscan el perfeccionamiento físico) y tal peligrosidad aumenta si el caso al abandonar su tratamiento vuelve a convertirse en agente positivo.

\section{Señor R.V. (calle Víctor Cuccuini)}

El Señor V. no se encontraba en casa. Hablé con su hermana casada (dueña de casa y me dijo que su hermano estaba separado de su familia y vivía con ella). Tuve que decirle que buscaba al Señor V., porque éste había abandonado el tratamiento y ella dijo, pero mire que mentiroso si ayer no más me dijo que tenía que levantarse temprano para ir a tomarse los remedios al Consultorio. Por otra parte agregó que no se trataba de un niño chico y que ella lo arreglaría. Le dejé dicho que pasara por el Consultorio, pero no lo hizo.

2da. Visita: En vista de que el Señor V. no fue a controlarse volví a visitarle el 21 del presente, le encontré en su casa y conversamos alrededor de un cuarto de hora. $\mathrm{Al}$ preguntársele que por qué no iba por cerca de casi un mes él dijo que sólo había faltado a seis sesiones (es decir sólo dos semanas), pero yo le dije que su tarjeta indicaba que el período de ausencia es mayor, pero que de todos modos lo que interesaba era que retomara su tratamiento ya que era éste la única vía de curación posible. Me dijo que habia dejado de asistir, porque el practicante era muy seco y terco. Al preguntarle por qué, dijo: mire, si llego temprano atiende primero a las señoras con guagua, si me atraso me dice que ya no me puede atender y para darle un ejemplo el otro día estaba citado para el lunes y fui el martes y me dijo que no me podía tratar. Le expliqué que acerca de sus primeras observaciones tendría que comprobar de una manera discreta lo que decia y que en el segundo caso el practicante habia actuado bien, porque de otra manera el espaciamiento necesario que requiere el tratamiento se perdería y valdría la pena, por último, que se tomaran todos los medicamentos de una vez. Se le explicó que desde el punto de vista del tratamiento eso no era ninguna solución. Después de esta segunda visita se comprometió a volver al tratamiento.

En el caso del Señor D. así como el caso del Señor V. parece interesante destacar que la presión que se ejerza por parte del Consultorio sobre el enfermo debe ser fuerte y provenir directamente de una persona investida o a la que el caso le adjudique un alto status. El hecho de la mera citación no parece surtir mucho 
efecto y el Sr. Rozas me dice que hay a los cuales se les ha dejado hasta seis citaciones y no han aparecido, por lo que ha habido que darlo de baja y tampoco el hecho de la presencia de un auxiliar de terreno. Pareciera decisivo que una autoridad más alta (un médico o un estudiante de medicina) hiciera las citaciones y hablara directamente con los enfermos diciendo cosas tales como: que la ausencia estaría determinando la posibilidad de crear una ley de asistencia obligatoria al tratamiento y el que la infringiera por motivos injustificados sería citado en forma y si no apareciera perdería derechos previsionales, etc. O que si no se presenta al Consultorio una unidad ambulante, le hará los tratamientos en la calle (inyección y pastillas tomadas frente a los vecinos no debe ser agradable para el caso). Falta por ver si después de esta segunda visita el caso fue a controlarse.

En parte lo que expresamos más arriba se explica, teóricamente, por el fenómeno de que la imitación cultural (aprendizaje de normas de salud) se beneficia cuando es impartido por elementos ejemplarizadores, de alto status. Por ejemplo, en los casos de mostrar que las aguas servidas pueden ser potables es el Alcalde de la Comunidad quien bebe el primer vaso, en presencia de todos. O los clásicos ejemplos del Perú en que el hervido del agua fue seguido como norma porque el médico tomaba agua hervida, y no por las condiciones asépticas del agua hervida.

Así, pues, en Chile, se puede obtener un flujo de normas culturales de salud, utilizando los promotores con status, entre las tres culturas (indígena, popular y científica).

ANALISIS MATERIAL CUALITATIVO

(Cédula No 12)

La enferma además de la TBC padece de epilepsia, ha sufrido en sus tres partos ("malos partos") y enferma durante los embarazos y en defintiva cree que va a morir atropellada y no de alguna enfermedad patológica. Esto es tema de discusiones con su marido.

Resulta interesante su situación afectiva ya que al preguntarle por sus padres responde que no se visitan y dice "nunca me llevé bien con ellos". A los dos años me mandaron donde un matrimonio, éramos 16 hermanos. Volví a mi casa a los 12 años y me dieron un mal trato muy angustioso, me pegaron mucho quizás pienso yo, porque no me querían.

Al llegar al punto del conocimiento de las formas del contagio de la TBC agregó y por los microbios. Hasta este momento se los imaginaba como pajaritos o bichitos y en el dibujo que se le pidió hiciera los muestra como un gusano que según ella en su tamaño natural tiene alrededor de unos 2 centímetros de largo y unos tres milímetros de ancho. Sabido es que en campañas de salud contra pediculosis, el uso de dispositivos con "piojos" de $20 \mathrm{cms}$., producen negativa del público sobre haber visto piojos. 
Al preguntársele sobre la conducta o actitudes de las enfermas frente al tratamiento en el hospital confesó que durante el primer tiempo las tomaba, pero que como eran desagradables empezó a imitar a muchas enfermas que las botaban a los baños. Al preguntársele si alguien las vigilaba mientras las tomaban respondió que sólo a algunas enfermas, a unas muy jóvenes y a las que las auxiliares las habían sorprendido botando los remedios y habían dado aviso al $\mathrm{Dr}$. El resto no eran sospechosas así que no se las vigilaba. Por otra parte resulta sintomático el hecho de que si las enfermas se internan para hacer reposo absoluto en el hospital éstas digan no haberlo hecho casi nunca, pues en las horas dedicadas a las siestas se ponían a leer o a conversar o a hacer algunos pasos de baile.

Resulta también interesante el que en varios de los entrevistados y con la presente, $C C$ digan no haber conversado del tema enfermedad TBC con sus compañeros durante su permanencia en el hospital.

\section{TEMOR AL CONTAGIO:}

Al preguntárseles por su motivación a la asistencia al consultorio entre algunas cosas que surgieron en la conversación dijo "No me gusta ir a los Consultorios ni a los hospitales para no contagiarse de otras enfermedades. He traído a mis niños sanos a control y a los dos o tres días los he tenido que traer de vuelta con resfrío".

En relación al tratamiento manifestó estar hostigada de las pastillas y tenerle miedo al practicante y no vaciló en contestar pregunta 8.2. que si se las llevara a su casa las botaría.

\section{SOBRE ALGUNOS TRATAMIENTOS POPULARES}

Aquí algunos Tratamientos Populares en relación a la TBC Pulmonar $y$ los Agentes que inducen a estos Tratamientos

\begin{tabular}{lll}
\hline $\begin{array}{l}N^{\circ} \text { de } \\
\text { Cédula }\end{array}$ & Aconsejado por & Tratamiento \\
\hline 01 & No lo visitan & $\begin{array}{l}\text { Tilo con limón -criogenina con Salofeno- pílsener con sal y } \\
\text { limón. }\end{array}$ \\
02 & Amigo & $\begin{array}{l}\text { a) Le dio remedios que no se acuerda, le puso rayos y le dijo que } \\
\text { no tenía nada. }\end{array}$ \\
a) Médico & b) Le dijo que fuera al hospital.
\end{tabular}



a) Vecino
b) Amigos
c) Practicante

a) Amigo

b) Amigos Amigos

\section{Una Señora}
a) Una Señora
b) El Patrón del marido
c) Amigos

a) Practicante

b) Mamá, Papá

Coramina-Breacol para la tos, jugo de limón en la mañana, coramina se la dieron en la farmacia, las hierbas las aprendió de su tío que curaba gente, el matico lo usaba para las heridas y creía que le hacían bien para la enfermedad, no tenía fe en su tío y su tío no tenía fe en los médicos, a él lo curaba una hija que todavía vive.

Machacar una cabeza de ajo pelada y mientras hervía se le agregaba un corto de aguardiente, se tomaba un cortito día por medio.

Que fuera al médico (hospital) por las hemorragias en la noche.

Toronjil, palqui, y maqui hervido en un litro de agua reducido a medio litro, tomar las veces que quiera.

a) Machacar 4 cabezas de ajo y tenerlas 9 días al aire - tomaruna cucharada antes de la comida, se sintió con alivio.

b) Tabletas de vitaminas que eran buenas para el pulmón.

c) Que comiera huevos duros y no blandos, los huevos fritos -eran malos- le daba jugo de zanahoria con jugo de naranja.

a) Jugo de tunas refregado y expuesto al sereno en la noche, tomar por 9 mañanas en ayunas.

b) Una malta con dos cabezas de ajo machacados después de almuerzo dos o tres veces por semana.

a) Carne de perro asada, los huesos de perro hervidos y tomarse las sopas.

b) Jugo de carne de caballo a bañomaría en agua con dientes de ajo 3 ó 4 veces por semana.

c) Una taza de leche hervida con 2 dientes de ajo al día.

a) Cebolla rallada en las mañanas.

b) Picar la carne de vaca chiquitita cocerla a baño María y tomar el jugo de la carne las veces que quiera.

c) Rallar media taza de zanahoria, dejarla al sereno y ponerle una cruz de palqui, tomar durante 7 días.

a) Ajo con alcohol de los Vilos.

b) Vino añejo con huevo - extracto de ajo- leche con ajo.

Fue directo al Consultorio, no tomó remedios caseros.

Leche con ajo - vino añejo con huevo (no los tomó).

Es mejor acudir al médico, no hizo caso a tratamientos caseros, no se acuerda de ninguno. 


\begin{tabular}{|c|c|c|}
\hline $\begin{array}{l}N^{0} \text { de } \\
\text { Cédula }\end{array}$ & Aconsejado por & Tratamiento \\
\hline 18 & $\begin{array}{l}\text { a) Familiar } \\
\text { b) Amigo } \\
\text { c) Amigo }\end{array}$ & $\begin{array}{l}\text { a) Ajo con paico y matico -jugo de cebollas al sereno. } \\
\text { b) Caracoles vivos con azúcar y leche. } \\
\text { c) Vino añejo en carne cruda. }\end{array}$ \\
\hline 19 & - & - \\
\hline 20 & Amigos & Malta con ajo y parafina. \\
\hline 21 & $\begin{array}{l}\text { a) Familiar } \\
\text { c) Enfermo del } \\
\text { hospital }\end{array}$ & $\begin{array}{l}\text { a) Ajo con leche -carne cruda con ajo. } \\
\text { b) Agua de Hilacha (pasto del cerro). } \\
\text { c) Flor de la Piedra en agua hervida, dejarla al sereno. }\end{array}$ \\
\hline 22 & Amigos & Nueces con plátano - ajo con leche. \\
\hline 23 & - & - \\
\hline 24 & - & - \\
\hline 25 & Familiar & Ajo con aceite. \\
\hline 26 & - & - \\
\hline 27 & Familiar & Cebolla con el jugo de la carne de caballo. \\
\hline
\end{tabular}

Estos tratamientos pertenecen a la cultura popular. Es importante que sean conocidos por el médico o la cultura científica; por dos razones:

$1^{\circ}$. Es posible encontrar en ellos, algunos principios positivos para las terapias. Por ejemplo: el poder bactericida del ajo. Hoy día la O.M.S. tiene un Departamento especial para estudiar los efectos objetivos de medicamentos populares, en varios países. Esto ocurre en U.S.A., Italia, México, Rusia, etc. En algunos casos, los Ministerios de Salud de estos países envasan y "timbran" con un visto bueno estos medicamentos. Es un visto bueno científico a elementos de la cultura popular de salud. En Chile, no hay una recepción muy activa a este tipo de contacto.

$2^{\circ}$. Este conocimiento mejora al "rapport" entre médico científico y paciente popular. Es decir, acerca las dos culturas o subculturas.

\footnotetext{
NotA: Las observaciones sobre T.B.C. plantean el conflicto entre cultura de salud tradicional y oficial. La vigencia se apoya en el etnocentrismo con que hoy la medicina oficial chilena mira a la medicina popular. Este etnocentrismo ha sido comprobado en Chile en un reciente estudio de Medina et als. $X, 1986^{*}$. En Chile parece haber una resistencia y ceguera generalizada frente a la medicina popular y a la acción de los agentes populares, ignorando la potencialidad de recursos que ella ofrece para la salud.
} 